\title{
ROTATOR-CUFF TEAR OF THE HIP
}

\author{
T. D. BUNKER, C. N. A. ESLER, W. J. LEACH \\ From the Princess Elizabeth Orthopaedic Hospital, Exeter, England
}

We describe an apparently unreported finding during hip operations: a tear at the insertion of gluteus medius and gluteus minimus. This defect may well be known to many surgeons with experience of hip replacement and hemiarthroplasty for fractures of the neck of the femur, but a Medline search has failed to find a previous description.

We made a prospective study of 50 consecutive patients with fractures of the neck of the femur to quantify the incidence of this condition: $11(22 \%)$ had such a tear.

J Bone Joint Surg [Br] 1997;79-B:618-20.

Received 24 June 1996; Accepted after revision 24 February 1997

We have observed, on occasion during hip operations, the presence of a tear in the tendinous insertion of the anterior third of gluteus medius and the tendon of gluteus minimus, where they insert into the greater trochanter (Fig. 1). This finding has implications for the strength of closure of the anterior and posterior flaps after a direct lateral or Hardinge approach to the hip. We have called this condition 'rotator-cuff tear of the hip' since it shares many features with its better known equivalent in the shoulder.

\section{CLINICAL INCIDENCE AND FEATURES}

We studied 50 consecutive patients with fractures of the neck of the femur prospectively to determine the incidence

T. D. Bunker, FRCS, FRCS Ed, Consultant Orthopaedic Surgeon Princess Elizabeth Orthopaedic Hospital, Wonford Road, Exeter, EX2 4UE, UK.

C. N. A. Esler, Senior Registrar

Leicester Royal Infirmary NHS Trust, Infirmary Close, Leicester LE1 5WW, UK.

W. J. Leach, FRCS, Consultant Orthopaedic Surgeon

Glasgow Royal Infirmary, Glasgow G4 OSF, UK.

Correspondence should be sent to Professor T. D. Bunker.

(C)1997 British Editorial Society of Bone and Joint Surgery 0301-620X/97/47033\$2.00 of such cuff tears of the hip and found 11 lesions (22\%). The tear was interstitial in three, small $(0.5$ to $1 \mathrm{~cm})$ in two and large $(2$ to $3 \mathrm{~cm})$ in six patients. The mean age of patients with a tear was 83.4 years and for the whole group 83.5 years (56 to 98 ).

The typical appearance is that of a circular or oval defect in the conjoint tendon of insertion of gluteus medius and gluteus minimus. The tear usually has rolled, mature edges, and is often associated with the presence of free fluid in the trochanteric bursa when the fascia lata is opened. The bony surface of the greater trochanter is visible through the tendinous defect and is often eburnated (Fig. 2). The bone deep to the tear usually shows a reactive sclerosis with heaped-up bone and some osteophytes, particularly on the anterior edge of the sclerotic area. These may be quite large and are sometimes visible on a radiograph (Fig. 3), in association with sclerotic lines and small cysts.

These radiological features were visible in six of our 11 patients with a proven cuff tear of the hip. Two had no such changes and in one the edge of the trochanter was off the edge of the pelvic radiograph. Two patients with interstitial tears both had normal radiological appearances. The changes were present in $55 \%$ of all tears and in all patients with large tears. Two of the 39 patients with normal gluteus insertions showed minor radiological changes in the greater trochanter.

\section{CLINICAL SIGNIFICANCE}

Tears have been seen both in patients with primary osteoarthritis during hip replacement and in the reported hemiarthroplasty patients; the tendinous tear or defect occurs at the point of separation of the anterior and posterior flaps which are created during the direct lateral or Hardinge approach to the hip. ${ }^{1}$ It may extend in both anteroposterior and craniocaudal directions, and give difficulty in surgical repair of the anterior flap. Detachment of this flap may contribute to weakness and a Trendelenburg gait.

Simple repair of the flap is unlikely to reattach firmly to the underlying sclerotic bone; a large anterior osteophyte on the greater trochanter may prevent closure. In such a case, the osteophyte should be excised and the sclerotic area decorticated to allow the flap to heal to good bleeding 


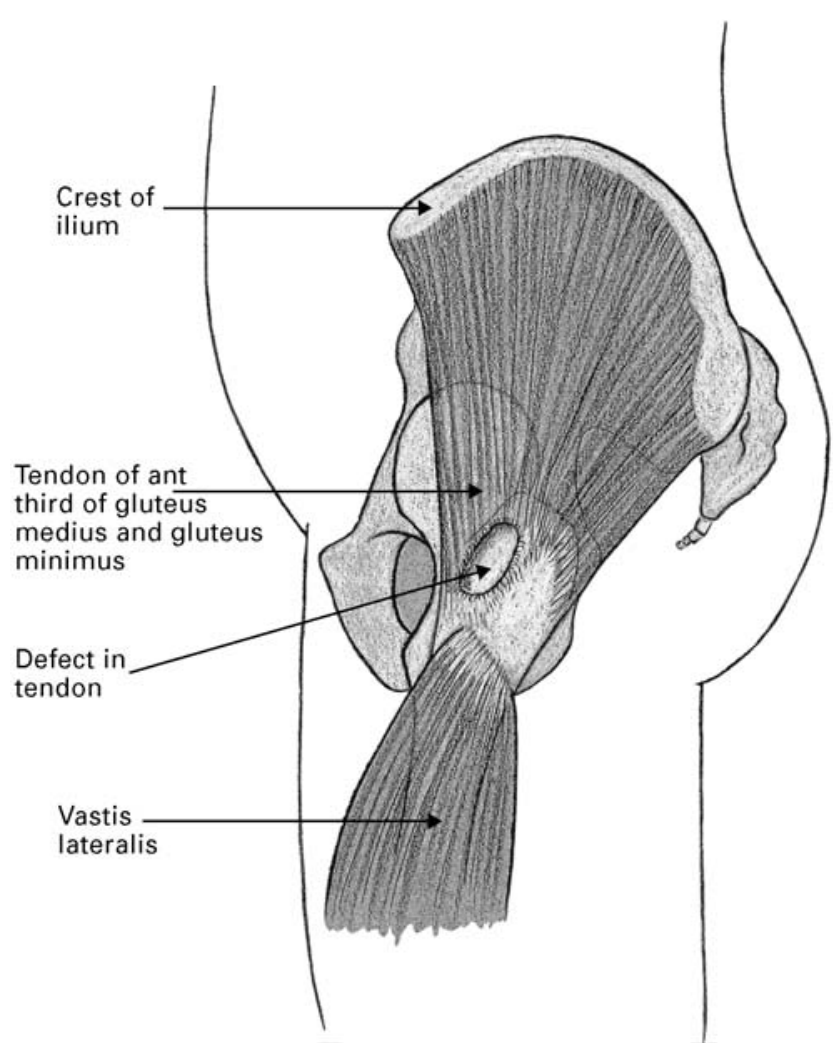

Fig. 1

Diagram showing the site of the tear.

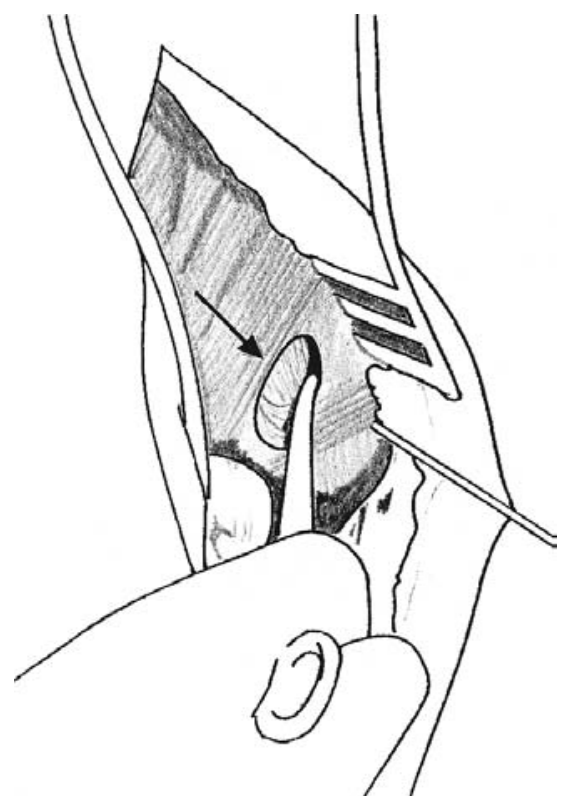

bone. The anterior flap can then be sutured to the posterior flap, but a repair which is weak in its central portion should be treated by three intraosseous sutures to provide direct reattachment, as in the repair of rotator-cuff tears of the shoulder. ${ }^{2}$ We have not found it necessary to use suture anchors, and our series was too small to show any measurable difference between the performance of hips with normal muscle insertions and those with repaired defects.

\section{DISCUSSION}

There are similarities between tears of the insertion of gluteus medius and minimus and those of the tendon of supraspinatus in the shoulder. The hip and the shoulder have some common anatomical features: each has a powerful internal rotator which inserts into the lesser trochanter/tuberosity (iliopsoas and subscapularis), two abductors which insert into the greater trochanter/tuberosity (gluteus minimus and medius and supraspinatus and infraspinatus) and a tendon crossing the head (long head of biceps and the reflected head of rectus femoris). Tears of the rotator cuff of the shoulder always start in the supraspinatus tendon, which is the analogue of gluteus minimus in the hip. In the hip, such a tear probably starts in the insertion of gluteus minimus near the digital fossa in the front of the greater trochanter. This is often the site of tiny interstitial tears, which have the appearance of tendon fibre

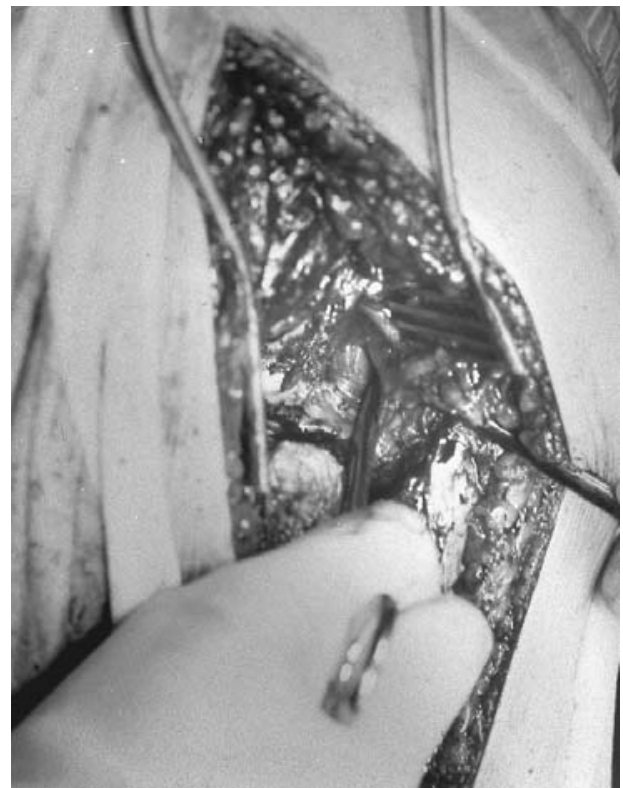

Fig. 2

Diagram and photograph taken at operation illustrating the tear. 


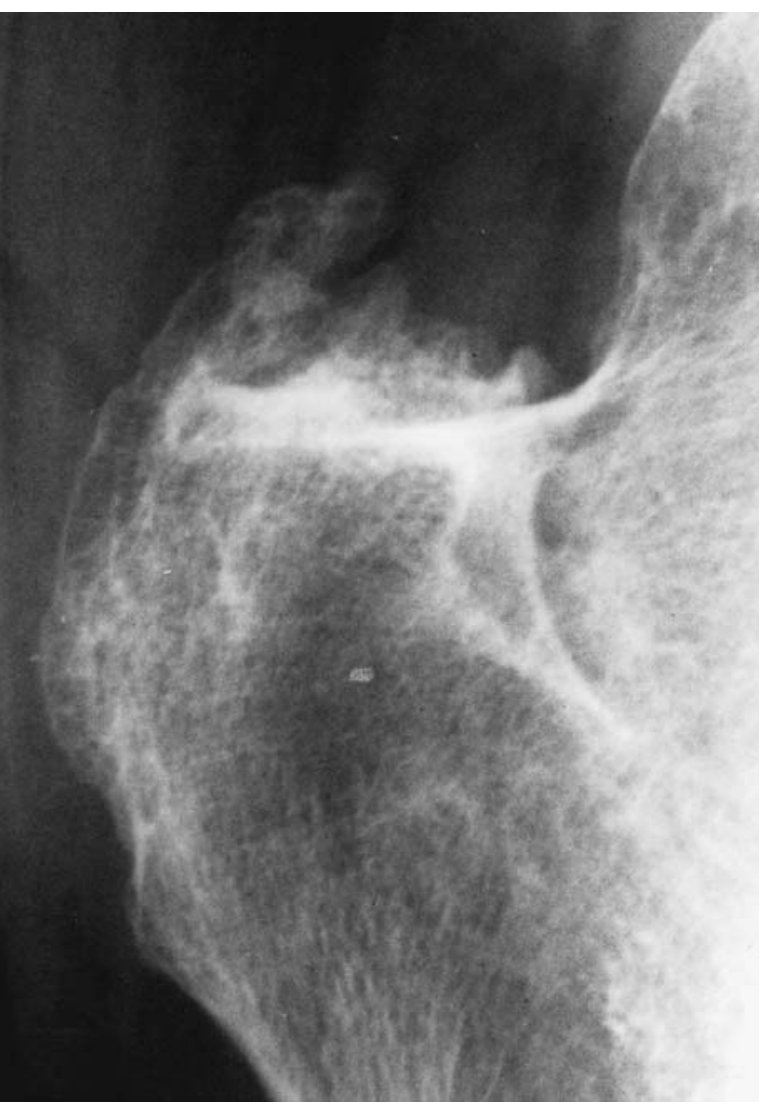

Fig. 3

Radiograph of the greater trochanter showing the osteophytes and sclerosis with some cystic change. failure. In the shoulder, large tears affect supraspinatus and the anterior border of infraspinatus and in the hip they involve gluteus minimus and the anterior third of the insertion of gluteus medius. Rotator-cuff tears in the shoulder are related to increasing age and often have mature, rolled edges ${ }^{3}$ similar to those which we describe in the hip. An increasing prevalence with age may account for our seeing more tears in patients with hip fractures than in those having hip replacement. Rotator-cuff tears at both the hip and the shoulder cause weakness and are difficult to repair, and have similar radiological appearances.

Rotator-cuff tears of the shoulder present with pain from impingement on the acromion and the coracoacromial ligament. At the hip there is no impingement and therefore no pain. Pain attributed to trochanteric bursitis, however, may be secondary to tearing of the gluteal muscles. Severe rotator-cuff tears of the hip can often be suspected from pelvic radiographs; this enables the condition to be diagnosed before operation and allows proper preparation for its repair.

No benefits in any form have been received or will be received from a commercial party related directly or indirectly to the subject of this article.

\section{REFERENCES}

1. Hardinge K. The direct lateral approach to the hip. J Bone Joint Surg [Br] 1982;64-B:17-9.

2. Codman EA. Ruptures of the supraspinatus tendon and other lesions in or about the subacromial bursa. Boston, Thomas Todd \& Co, 1934.

3. Bunker TD. Tendon disorders of the shoulder and elbow. Current opinion in orthopaedics. 1995;7;IV:68-72. 